Rev. Interd. em Cult. e Soc. (RICS), São Luís, v. 6, n. 2, p. 265-270, jul./dez. 2020

ISSN eletrônico: 2447-6498

BEACH, Toby y MILLER, Thomas. Aerial America. Berkeley: Tusker Television LLC. 2019, 3240 minutos.

\title{
Resenha Aerial America
}

JOSÉ ANTONIO ABREU COLOMBRI CORREIO

Doutor na Universidade de Alcalá (Espanha, Alcalá de Henares), no programa de "Estudos Norte-Americanos. Ciências Sociais e Jurídicas".

abreucolombri@gmail.com

Palavras-chave: Estados Unidos. Cultura Popular. Historia. Patrimonio arquitectónico. Representación geográfica

Desde la generalización de la TV por cable, los canales han aumentado considerablemente y las audiencias se han fragmentado progresivamente. Dicho aumento de canales ha provocado que el tiempo de emisión se expanda, por ese motivo la producción de contenidos documentales se ha convertido en un recurso muy utilizado por los diseñadores de la programación televisiva. Indirectamente, la fragmentación de las audiencias, ha conllevado el surgimiento de áreas de especialización temática. Esas dos variables han hecho posible que la divulgación de las ciencias sociales y las humanidades, a través de producciones documentales, cristalice en una variada oferta audiovisual.

Las tendencias actuales de la industria audiovisual y la demanda prolongada de documentales de divulgación cultural han hecho posible que se programen series de gran extensión. Este es el caso de Aerial America (Tusker Television LLC), una serie de documental diseñada para ser emitida en televisión (Smithsonian Channel) durante varios años. La serie duró casi una década, a través de la emisión por cable en Estados Unidos y Canadá, la emisión satelital en Irlanda y Reino Unido y la emisión digital Apple TV (recepción digital multimedia). Este tipo de producciones documentales tiene un gran valor pedagógico, sirve como producto de entretenimiento, es un recurso de promoción turística multidimensional y presenta muchos datos novedosos en el guion. El documental ha sido traducido a varios idiomas y distribuido en varios países de América del Sur y Europa. En España, fue comercializado con el título de América desde el aire. 
Rev. Interd. em Cult. e Soc. (RICS), São Luís, v. 6, n. 2, p. 265-270, jul./dez. 2020

ISSN eletrônico: $2447-6498$

En la primavera de 2010 se puso en marcha este proyecto gigantesco, que se marcó como objetivo divulgar aspectos socio-culturales, históricos, naturales y patrimoniales de todas las regiones del país. Esta labor de divulgación fue proyectada inicialmente para realizarse por estados, pero debido al éxito, los productores decidieron ampliar los contenidos del proyecto documental mediante nuevos marcos espaciales y conceptuales: monumentos nacionales, reservas naturales, áreas climáticas, formas arquitectónicas, grandes infraestructuras, tipologías urbanas, estilos rurales, et cetera. Cada capítulo es una síntesis de elementos culturales, geográficos, históricos, artísticos y sociales. La serie se compone de setenta y dos capítulos, que fueron emitidos semanalmente. Cada capítulo tiene una duración aproximada de cuarenta y cuatro minutos.

La primera temporada se emitió en 2010, durante los meses de julio y agosto. "California" (primero) fue el territorio elegido para causar un gran impacto visual sobre las audiencias, se recogen estereotipos regionales (playas, viñedos y grandes conurbaciones) y elementos poco conocidos de la historia y las instituciones estatales. La compañía grabó y edito este capítulo fue Taikuli Productions, lo hizo de forma exclusiva, porque el resto de capítulos fueron producidos por Tusker Television LLC.

"Hawaii" (segundo) es presentado como un paraíso natural, tomando como referencia las principales islas del archipiélago. Se visitan las diferentes zonas de "Virginia" (tercero), "Connecticut" (cuarto), "Tennessee" (quinto) y "Vermont" (sexto) mediante la grabación de los lugares históricos y núcleos patrimoniales. "Arkansas" (séptimo) es una mezcla de relato histórico y descripción de paisajes naturales. "Rhode Island" (octavo) es puesto en medio de su contexto geográfico y se resalta la belleza arquitectónica, las líneas de costa y las masas arbóreas.

La segunda temporada (del capítulo noveno al capítulo décimo octavo) también se emitió en los meses de verano, en 2011. Los técnicos de grabación se quedan obnubilados con la inmensidad de las líneas costeras en "Maine" (noveno), todo lo demás tiene una posición secundaria. "Oregon” (décimo) toma en consideración la evolución histórica de la región, las explotaciones económicas centenarias y, sobre todo, la riqueza natural del estado: bosques, lagos, cataratas, cauces fluviales, playas, acantilados y archipiélagos. "Washington” (décimo cuarto) 
Rev. Interd. em Cult. e Soc. (RICS), São Luís, v. 6, n. 2, p. 265-270, jul./dez. 2020

ISSN eletrônico: $2447-6498$

tiene una estructura y una secuencia narrativa muy similar al capítulo de Oregón. "Georgia" (décimo tercero) es presentado como una concentración paradigmática de toda la región sureña.

"South Carolina" (décimo primero), "Massachusetts" (décimo segundo), "New Hampshire" (décimo quinto), "Maryland \& Delaware" (décimo sexto), "North Carolina” (décimo séptimo) y "New York" (décimo octavo) son episodios de estados situados en la parte más oriental del país, con un acervo cultural vinculado al Atlántico y con una perspectiva histórica muy amplia. Dichas descripciones históricas están vinculadas al concepto de pueblo y a las diferentes formas de administración política y económica, que van desde los orígenes coloniales al momento presente. El final de la segunda temporada fue un momento de inflexión en la serie documental, porque comenzó a alcanzar unos niveles de difusión muy altos y una gran resonancia entre las audiencias regionales.

La tercera temporada se emitió en el año 2012, en dos tandas: invierno (del capítulo décimo noveno al capítulo vigésimo quinto) y otoño (del capítulo vigésimo sexto al capítulo trigésimo). "Louisiana" (décimo noveno): estilos de vida alternativos, zonas pantanosas y cultura local. "New Mexico" (vigésimo): imaginería popular, hitos de la colonización, el mito de la frontera salvaje y tecnología militar (proyectos nucleares). "Michigan" (vigésimo primero): patrimonio industrial, surgimiento del movimiento sindical, reconversión económica durante la Segunda Guerra Mundial y prosperidad automovilística de posguerra. "Nevada" (vigésimo segundo): zonas de experimentación militar, historia de la conformación del estado, la ciudad de las luces y los contrastes del desierto. "Colorado" (vigésimo tercero): riqueza natural y el mito del salvaje Oeste. "Mississippi" (vigésimo cuarto): estilos de vida, cultura popular, contrastes paisajísticos y los elementos geográficos (como objeto de investigación histórica). "Pennsylvania" (vigésimo quinto): símbolos culturales, historia fundacional, claves del desarrollo económico inicial, proceso de industrialización y patrimonio urbanístico.

La segunda sesión comenzó a principios del mes de octubre. "Florida" (vigésimo sexto): principales ciudades, playas y bahías, lugares vacacionales y parque naturales. "Kansas" (vigésimo séptimo): agricultura extensiva, espacios naturales y estilos de vida. "Alabama" (vigésimo octavo): cultura popular, historia decimonónica e identidad sureña. "Oklahoma" (vigésimo noveno): iconos sociales, mundo rural y escenarios cinematográficos. "Arizona" 
Rev. Interd. em Cult. e Soc. (RICS), São Luís, v. 6, n. 2, p. 265-270, jul./dez. 2020

ISSN eletrônico: 2447-6498

(trigésimo): pasajes montañosos, puestas de sol, crónica de sucesos estatales, fenómenos históricos e iconos sociales.

La cuarta temporada volvió a emitirse en verano, en los meses de julio y agosto de 2013 (del capítulo trigésimo primero al capítulo trigésimo segundo): "Amazing Destinations", "Montana", "Ohio", "Minnesota", "Made in the USA", "West Virginia" y "Beyond Hollywood". En los cuatro episodios dedicados a estados se retratan los principales acontecimientos históricos, las reservas naturales y los aspectos arquitectónicos. En los tres episodios dedicados a temáticas específicas se hace un repaso de los lugares más llamativos del territorio nacional (no filmados anteriormente), la historia y el patrimonio industrial estadounidense (por regiones productivas) y los lugares más famosos del territorio nacional (conocidos popularmente por ser escenarios cinematográficos). A partir de esta cuarta temporada, se van intercalando los contenidos temáticos, para que la serie documental pudiese tener una mayor extensión. Ahora, la fórmula exitosa creaba un nuevo marco de trabajo de edición, más allá del territorio estatal como objeto de grabación y objetivo de divulgación.

La quinta temporada se emitió desde las últimas semanas del invierno hasta las últimas semanas del verano (del capítulo trigésimo octavo al capítulo cuadragésimo octavo) del año 2014. A grandes rasgos, existe una uniformidad de contenidos relacionados con los parques naturales, infraestructuras, cultura popular e historia local: "Texas" (trigésimo octavo), "Idaho" (capítulo trigésimo noveno), "Kentucky" (cuadragésimo), "Utah" (cuadragésimo primero), “The Dakotas" (cuadragésimo segundo), "Wyoming" (cuadragésimo tercero) y "Nebraska" (cuadragésimo cuarto). Todos los elementos de edición sobre Dakota del Norte y Dakota del Sur son comprimidos en un solo episodio. En el caso de Alaska, los elementos de edición se desdoblan en dos episodios, por la inmensidad territorial y la riqueza de los paisajes: "Alaska's Fire and Ice" (cuadragésimo sexto) y "Alaska's Call of the Wild” (cuadragésimo séptimo). En los dos episodios temáticos, se toman grabaciones de todas las regiones. "Best Small Towns" (cuadragésimo quinto) contiene centros urbanos muy reducidos, con peculiaridades culturales y patrimoniales; "Wilderness" (cuadragésimo octavo) prospecta los climas más extremos y las orografías más singulares. 
Rev. Interd. em Cult. e Soc. (RICS), São Luís, v. 6, n. 2, p. 265-270, jul./dez. 2020

ISSN eletrônico: $2447-6498$

La sexta temporada se emitió en la primavera de 2015 (del capítulo cuadragésimo noveno al capítulo quincuagésimo quinto). En esta nueva edición de la serie documental se mantiene la misma fórmula temática, pero con un enfoque de guion nuevo, aportando algunas secuencias cuantitativas para comentar aspectos económicos, demográficos, culturales, históricos, medioambientales, et cetera. Las curiosidades de la cuantificación matemática están presentes en la edición de "Washington D.C." (cuadragésimo noveno), "Wisconsin” (quincuagésimo), "New Jersey" (quincuagésimo primero), "Indiana” (quincuagésimo segundo), "Iowa” (quincuagésimo tercero), "Missouri" (quincuagésimo cuarto), "Illinois" (quincuagésimo quinto).

La séptima temporada se emitió en la primavera y el verano de 2016 (del capítulo quincuagésimo sexto al capítulo sexagésimo séptimo). Aquí se van intercalando episodios que abordan temáticas concretas y espacios estatales: “On The Water" (quincuagésimo sexto), "Puerto Rico \& US Virgin Islands" (quincuagésimo séptimo), "Natural Wonders" (quincuagésimo octavo), "The Great Plains" (quincuagésimo noveno), "Roadside Attractions" (sexagésimo), "Man-Made Marvels” (sexagésimo primero), “The South” (sexagésimo segundo), "Trailblazers" (sexagésimo tercero), "New England" (sexagésimo cuarto), "The Wild West" (sexagésimo quinto), "Southern California" (sexagésimo sexto) y "Northern California" (sexagésimo séptimo). Muchos episodios vuelven a tratar temas ya vistos, pero esta vez desde una perspectiva diferente o con un mayor grado de especialización. Concretamente, el estado de California vuelve a recibir atención, esta vez los contenidos se desdoblan en dos episodios (Tusker Television LLC). Las audiencias comenzaron a dar las primeras muestras de agotamiento, después de más de sesenta ediciones. La productora solo emitió un programa, entre julio de 2016 y marzo de 2019.

La temporada octava (2017) y la temporada novena (2019) representan la expansión artificial de la serie (del capítulo sexagésimo octavo hasta el final), debido a la fidelidad de la audiencia y con el objetivo de optimizar documentos de grabación inéditos. Ese material inédito se combina con material nuevo en "New York City 24" (sexagésimo octavo), "Yellowstone" (sexagésimo noveno), “Boston 24" (septuagésimo), "Dallas-Fort Worth 24" (septuagésimo primero) y "Great Cities" (septuagésimo segundo). El 22 de diciembre de 2019 concluyó la emisión de Aerial America de forma abrupta y, posiblemente, como consecuencia del agotamiento de los seguidores. 
Rev. Interd. em Cult. e Soc. (RICS), São Luís, v. 6, n. 2, p. 265-270, jul./dez. 2020

ISSN eletrônico: 2447-6498

Cada episodio tiene un enfoque diferente y genuino, pero dentro de un marco de trabajo definido. La variedad de contenidos en la serie documental viene determinada por la multitud de materias a cubrir y por el intento de combinar contextos de grabación dinámicos. Este documental ha tenido un gran éxito de difusión, no solo por la audiencia, sino por las diversas reposiciones a lo largo del tiempo y por la comercialización fuera de los Estados Unidos. Este tipo de formato documental, por las cuestiones relativas a la temática, se convierten en un fantástico activo para el sector turístico. Las técnicas de grabación aéreas permiten plasmar unos imponentes espacios naturales y urbanos. Así que cualquier contenido de la serie documental estimula el turismo interior y la visita de millones de extranjeros cada año, contribuyendo en gran medida al desarrollo del turismo en todas las regiones del país.

\section{Ficha técnica}

Dirección de producción: Toby Beach y Thomas Miller. Fotografía de fotografía: Toby Beach y Thomas Miller. Guion: Jim Conrad, Toby Beach y Thomas Miller. Producción ejecutiva: Toby Beach, David Royle y Charle Poe. Productora: Tusker Television LLC y Taikuli Productions. Distribuidora: Smithsonian Channel. Técnica de grabación: digital. Idioma original: inglés. Género: documental (serie documental). Origen: Berkeley, California (USA). Duración: 372 minutos. Años: 2010-2019. 